\title{
Zambiapunga: cultura popular e processos educacionais baseados na construção e na afirmação das identidades
}

\author{
Pedro Rodolpho Jungers Abib ${ }^{1}$ \\ Núbia Cecília Pereira Santos ${ }^{2}$
}

\begin{abstract}
Resumo
Este trabalho tem como linha de análise os grupos de Zambiapunga, das cidades de Taperoá, Valença, Nilo Peçanha e Cairu, localizadas no Recôncavo Baiano, especificamente na região do Baixo Sul, conhecida também como Costa do Dendê. O Zambiapunga é um grupo formado por homens e mulheres, mascarados, com roupas coloridas, que desfilam, na madrugada, pelas ruas das cidades, convidando a população para participar da festa. De origem dos povos Bantus, levam às mãos tambores, enxadas, cuícas e búzios marinhos, seguindo um cortejo enfileirado de várias coreografias. O principal objetivo deste artigo é compreender, a partir das novas configurações que a noção de cultura popular assume na contemporaneidade, como os grupos Zambiapunga contribuem para a valorização e para o fortalecimento da memória, da identidade e da cultura local, bem como os processos de educação presentes nessa dinâmica.
\end{abstract}

Palavras-chave: Zambiapunga; cultura popular; memória; identidade; educação.

1 Professor da Faculdade de Educação e do Programa de Pós-graduação em Educação da Universidade Federal da Bahia (UFBA). Coordenador do Grupo de Pesquisa Griô-UFBA.

2 Universidade Federal da Bahia. Mestre em Educação. 


\title{
Zambiapunga: popular culture and education processes based on construction and affirmation of identities
}

\begin{abstract}
This work has as line of analysis the Zambiapunga groups, the cities of Taperoá, Valencia, Nile and Cairu, located in the Recôncavo Baiano, specifically in the Lower South, also known as Dende Coast. The Zambiapunga is a group of men and women, masks, with colorful clothes, parading in the morning, the streets of the cities, inviting the population to join the party. Of origin of the Bantu people, take the hands drums, hoes, marine cuícas and whelks, following a procession queued several choreographies. The main purpose of this article is to understand, from the new configurations that popular culture notion assumes nowadays, as Zambiapunga groups contribute to the development and strengthening of memory, identity and local culture as well as education processes present this dynamic.
\end{abstract}

Keywords: Zambiapunga; popular; culture; memory; identity; education.

\section{Introdução}

A Bahia, contemporaneamente, é definida como um estado rico, tanto em belezas naturais quanto em aspectos culturais, ao contrário do que acontecia na virada do século XIX e nas primeiras décadas do século XX, quando os "hábitos, as diversões e as brincadeiras ligadas às camadas populares eram vistas como viciosos, perigosos ou prejudiciais", porque, segundo as classes dominantes, retratava e exaltava as "velhas tradições ou costumes africanizados" (FONSECA, 1996 , p. 36). A partir das últimas décadas, porém, começa, na Bahia, um processo de valorização da produção simbólica de raízes africanas; assim, o candomblé, a capoeira, os blocos afro, o samba de roda, os cortejos, os reisados e as cheganças, 
entre outras manifestações culturais, passaram a ter certo destaque, tanto em alguns setores da mídia quanto nas produções acadêmicas, como representativos da riqueza cultural baiana, com ênfase para a importância do elemento negro-africano na constituição da mesma. O Zambiapunga é outro exemplo de manifestação cultural que passa a fazer parte desse contexto, sendo esse folguedo oriundo das cidades de Cairu, Nilo Peçanha, Taperoá e Valença. Interessante dizer que todas essas cidades estão localizadas no Recôncavo Baiano, na região do Baixo Sul ${ }^{3}$, conhecida também como Costa do Dendê (BRASIL, 2012).

O Zambiapunga é uma manifestação cultural originária das cidades antes citadas, organizada em grupos formados por dezenas de homens e mulheres, todos eles mascarados, com roupas de seda, multicoloridas, portando uma espécie de chapéu, em forma de cone, enfeitado de papel crepom; desfilam, todos os anos, na madrugada do dia primeiro de novembro, pelas ruas da cidade, convidando a população para, conjuntamente a eles, participarem da festa. Portanto, o objetivo deste artigo, que é proveniente de pesquisa acadêmica que culminou com a produção de uma dissertação de mestrado em Educação, na Universidade Federal da Bahia, foi compreender como os grupos do Zambiapunga, a partir do enfoque sobre a noção contemporânea de cultura popular, contribuem para a valorização e para o fortalecimento da memória, da identidade e das culturas locais, buscando ainda compreender os processos educativos presentes nessa dinâmica.

Dessa forma, este artigo divide-se em quatro subseções: a primeira busca compreender as novas configurações que a noção de cultura popular assume na contemporaneidade, a repercussão desse processo no âmbito das políticas públicas e como esse processo tem influenciado a retomada e a valorização de diversas tradições populares, dentre elas, o próprio Zambiapunga. A segunda busca contextualizar o folguedo, a partir de uma abordagem histórico-social. A terceira, empírica, assume a pesquisa como produto de construção social, buscando ouvir as vozes dos sujeitos. Por fim, a quarta busca potencializar diálogos e discussões

3 O Baixo Sul é uma região que abrange uma área de 7.168,10 km² e é composta por mais 14 municípios, sendo eles: Cairu, Camamu, Igrapiúna, Ituberá, Jaguaripe, Aratuípe, Valença, Nilo Peçanha, Taperoá, Teolândia, Wenceslau Guimarães, Gandu, Piraí do Norte e Presidente Tancredo Neves. 
sobre as questões dos grupos e da educação nos espaços e contextos investigados.

\section{Cultura popular: um conceito em movimento}

A virada do século marca transformações em todos os níveis das atividades humanas, o que implica em importantes mudanças no âmbito da economia, da política e, sobretudo, no âmbito da cultura, responsáveis por uma nova configuração da sociedade do terceiro milênio. A cultura passa a ser um lócus fundamental nesse processo, tanto no que diz respeito às novas tensões identitárias, que surgem com a crise do estado nacional liberal - que sempre manteve encoberta a questão das identidades múltiplas - quanto em relação ao papel que desempenha enquanto possibilidade de negociação na elaboração de estratégias de subjetivação que dão início a novos signos de identidade e a novas possibilidades de colaboração e de contestação, no ato de definir a própria ideia de sociedade.

A cultura, como define Homi Bhabha (2008), torna-se uma prática desconfortável, perturbadora, de sobrevivência e de suplementaridade entre a arte e a política, o passado e o presente, o público e o privado - na mesma medida em que seu ser resplandecente é um momento de prazer, esclarecimento ou libertação. Assim, a partir da cultura, desenvolve-se um conjunto de regras de criação e de interpretação da realidade que expressam tanto subjetividades quanto racionalidades próprias. Daí a possibilidade de pensar a cultura como representação e expressão de valores que organizam nossas ações e tornam a vida coletiva possível, na medida em que produz o compartilhamento de sentidos entre os iguais e a tradução de significados entre os diferentes. Tais processos simbólicos implicam certa materialidade; como nos alerta Canclini, "não existe produção de sentido que não esteja inserida em estruturas materiais" (CANCLINI, 1997, p. 17).

Em se tratando especificamente do termo "cultura popular", Stuart Hall (2002) avisa que definir conceitualmente o termo "popular" é quase tão difícil quanto definir o termo "cultura". Quando colocamos 
os dois termos juntos, então, as dificuldades podem se tornar imensas. Conforme o autor, a tradição popular constituía um dos principais locais de resistência às maneiras de controlar e de "reformar" o povo. É por isso que a cultura popular tem sido há tanto tempo associada às questões da tradição e das formas tradicionais de vida, e também por isso seu "tradicionalismo" tem sido mal interpretado, como mero impulso conservador, retrógrado e anacrônico. Afirma Hall que a cultura popular sempre foi luta e resistência, mas também apropriação e expropriação. Por isso, segundo ele, "no estudo da cultura popular, devemos sempre começar por aqui: com o duplo movimento de conter e resistir, que inevitavelmente se situa em seu interior" (HALL, 2002, p. 245). E continua o autor:

A cultura popular é um dos locais onde a luta a favor ou contra a cultura dos poderosos é engajada; é também o prêmio a ser conquistado ou perdido nessa luta. É a arena do consentimento e da resistência. Não é a esfera onde o socialismo ou uma cultura socialista - já formada - pode simplesmente ser "expressa". Mas é um dos locais onde o socialismo pode ser constituído. É por isso que a cultura popular importa. (HALL, 2002, p. 246)

Em recente publicação, Abib (2015) aponta para a necessidade de se compreender a cultura popular enquanto terreno de luta, onde as referências que remetem às memórias, às tradições e às identidades de determinados grupos sociais são requisitadas e disponibilizadas, num processo que gera reivindicações em torno do reconhecimento, da autonomia e do poder em vários campos, no âmbito da cultura hegemônica. Porém, continua o autor, não seria mais possível, hoje em dia, por exemplo, operar com a clássica divisão entre "cultura erudita", "cultura popular" e "cultura de massa" de forma tão simplificada como muito se fez. As novas configurações da cultura e a sua imensa teia de articulações e de relações estabelecida no âmbito das sociedades contemporâneas não permitiriam uma classificação tão estanque, visto que o trânsito de influências, arranjos e combinações faz com que os mais variados campos de atuação cultural se interpenetrem o tempo todo e em todas as direções. 
Dessa forma, os processos de hibridização cultural não podem ser desconsiderados nesse contexto, pois estruturas ou práticas culturais discretas, que existiam de forma separada, combinam-se para gerar novas estruturas, novos objetos e práticas, afastando de vez a possibilidade de analisar a cultura enquanto algo puro e homogêneo. Nos dias atuais, teóricos culturais como Hall (2002), Bhabha (2008) e Canclini (1997) apontam para algumas precauções ao se abordar a cultura popular como expressão da cultura e da identidade nacional. Diz Canclini, claramente:

O popular não deve por nós ser apontado como um conjunto de objetos (peças de artesanato ou danças indígenas), mas sim como uma posição e uma prática. Ele não pode ser fixado num tipo particular de produtos e mensagens, porque o sentido de ambos é constantemente alterado pelos conflitos sociais. Nenhum objeto tem o seu caráter popular garantido para sempre porque foi produzido pelo povo ou porque este o consome com avidez; o sentido e o valor populares vão sendo conquistados nas relações sociais. É o uso e não a origem, a posição e a capacidade de suscitar práticas ou representações populares, que confere essa identidade. (CANCLINI, 1997, p. 135).

Para o autor, outro desafio refere-se à necessidade de se entender o que mobiliza a importância dada à cultura popular como expressão de uma identidade mais genuína. Muitas vezes, a atenção dada à cultura popular é uma espécie de "invocação que legitima o poder das elites e obscurece a realidade de exclusão" (CANCLINI, 1997, p. 136). Há, aqui, uma sutil operação: ao se afirmar a existência da cultura popular, consolida-se uma espécie de negação.

Em vez de realidade autônoma ou como parte dependente de outros modelos culturais no interior de uma sociedade, a cultura popular pode ser também, aos olhos de Bhabha:

[...] pensada como uma das formas de representação e expressão simbólica que se materializa em práticas religiosas, lúdicas, artísticas e artesanais, que ora emergem de contextos e áreas simbólicas marcadas pela tradição ora expressam respostas a experiências de "sentenciamento da história - subjugação, dominação, diáspora, deslocamento. (BHABHA, 2013, p. 18). 
Há, portanto, uma necessidade de se compreender o que há de novo nesse convite atual sobre a importância da cultura popular, de forma a perceber transformações pelas quais essa noção vai passando no contexto da sociedade brasileira atual. A nova configuração de comunidades tradicionais, grupos e associações de cunho popular que têm se organizado em torno da reivindicação de seus direitos e do reconhecimento de seus saberes e práticas é um exemplo disso. Essa articulação tem ocorrido em diversos níveis e gerado um movimento social e político muito rico e significativo que se reflete em conquistas que já podem ser observadas no campo das políticas públicas, como: os vários editais públicos voltados para expressões da cultura popular;, prêmios para ações e experiências no campo da cultura, realizadas nas comunidades; reconhecimento dos saberes tradicionais dos mestres populares, a partir da tramitação de leis no Congresso Nacional, como a Lei dos Mestres ${ }^{4}$ e a Lei Griô Nacional ${ }^{5}$, que têm sido, inclusive, objeto de muitos conflitos e disputas envolvendo diferentes visões sobre o tema.

Acreditamos que essas novas configurações no campo da cultura popular dão consistência a uma definição de políticas culturais e se apresenta como demanda conceitual a ser enfrentada para a conformação do campo de estudos dessa área. Pode-se tomar como ponto de partida a noção de políticas culturais formulada por Canclini:

Estudos recentes tendem a incluir sob este conceito para todas as intervenções feitas pelo Estado e grupos comunitários, para orientar o desenvolvimento simbólico, satisfeito as necessidades culturais da população e obter consenso a um tipo de ordem ou transformação social. Mas, esta maneira de caracterizar o campo de política cultural precisa ser ampliados em tomar conta de caráter transnacional os processos simbólicos e materiais hoje em atualidade. (CANCLINI, 2001, p. 65).

A cultura não pode ser vista, conforme Abib (2015), somente como

$4 \mathrm{PLn}^{\circ}$ 1176/2011, de autoria do Deputado Edson Santos (PT-RJ), conhecida como Lei dos Mestres. Prevê formas de valorização dos mestres das culturas tradicionais, reconhecidos por suas comunidades, através de auxílio financeiro no valor de dois salários mínimos.

$5 \mathrm{PLn}^{\circ}$ 1786/2011, de autoria da Deputada Jandira Feghali (PCdoB-RJ), conhecida como Lei Griô. Prevê a proteção dos saberes tradicionais, através da garantia da transmissão desses saberes e fazeres da tradição oral nas escolas. 
entretenimento, e nem a população, somente como público consumidor. Parece que, lentamente, os gestores das políticas públicas nesse campo começam a reconhecer o papel do cidadão também como produtor de cultura, compreendendo a necessidade de estimular e de fomentar, através de financiamento público, iniciativas que permitam que a produção cultural se espalhe por todos os cantos do território nacional, e não somente nos nichos localizados nos "centros de excelência", tradicionalmente privilegiados com essas políticas. Esse é um avanço nas gestões de políticas culturais ainda a ser melhor consolidado no nosso país; porém, o papel que desempenham os sujeitos e os grupos ligados às manifestações das culturas populares tradicionais tem sido fundamental nesse processo.

Outro aspecto dessa questão que, segundo Abib (2015), significou um avanço muito grande nesse campo foram, sem dúvida nenhuma, as iniciativas relacionadas à identidade, à salvaguarda e aos direitos individuais e coletivos de diferentes criações, tornadas patrimônio imaterial popular, tais como o reconhecimento do Samba de Roda do Recôncavo Baiano, do Frevo e da Capoeira como Patrimônios Imateriais da Cultura Brasileira pelo IPHAN (Instituto do Patrimônio Histórico e Artístico Nacional), ocorrido recentemente. Tais iniciativas poderão representar, de agora em diante, um patamar importante de afirmação popular de criação cultural.

A cultura popular, em termos atuais, é definida em documento da Convenção para a Salvaguarda do Patrimônio Cultural Imaterial, da UNESCO $^{6}$. Ela envolve, conforme Carlos Rodrigues Brandão (2009), práticas sociais e representações por meio das quais uma comunidade cultural exprime sua identidade particular no seio de uma sociedade mais ampla. Essas formas culturais são, com frequência, comercializadas ou difundidas, mas, independentemente de suas finalidades, devem ser

\footnotetext{
6 Discussões e disputas envolvendo essa temática se cristalizaram com maior clareza por ocasião da votação da Declaração Universal sobre a Diversidade Cultural, em 2001, no âmbito da Unesco, e, posteriormente, em 2005, quando da aprovação da Convenção Sobre a Proteção e a Promoção da Diversidade das Expressões Culturais. Ambas as votações e seus respectivos textos são resultados de um longo processo de normatização, oficialização e dilatação do conceito de cultura no âmbito da Unesco, desencadeado com maior vigor a partir dos anos setenta e recrudescido nos anos noventa do século passado, a partir das demandas políticas, econômicas e simbólicas que surgiram nas últimas décadas do século XX.
} 
preservadas, no que tange aos seus modos de produção, à sua memória, aos seus sentidos e significados.

Justamente nesse momento em que a pesquisa que dá forma a este artigo se desenvolve, recebemos a notícia de que o IPHAN começa a realizar inventário com vistas ao reconhecimento do Zambiapunga como patrimônio da cultura brasileira. Portanto, é hora de conhecermos um pouco mais sobre essa intrigante manifestação da cultura popular.

\section{Ritmos, sons e caretas pelas ruas: Zambiapunga}

De origem dos povos bantus, advinda do Sudoeste do Continente Africano, na altura entre Congo, Angola, Zâmbia e Namíbia, os integrantes dessa manifestação levam às mãos tambores, enxadas, cuícas e búzios marinhos; seguem num cortejo enfileirados, valendo-se de variadas coreografias e pisadas firmes, que demonstram querer receber do solo a benção e a aprovação dos deuses.

A palavra Zambiapunga ${ }^{7}$ vem de Zambi ou Nzambi-a-Mpungu, que é o Deus Supremo dos povos bantus, cujas línguas possuem origem comum e, por isso, o termo "bantu" delimita um grupo linguístico africano, e não uma etnia. Segundo vocabulário construído por Aires Machado Filho e reproduzido por Nei Lopes (2006), a palavra Mpungu é sinônima de defunto. Yeda Castro $^{8}$ traduz, por sua vez, nzambi ampungu como o grande espírito, e saami ampunga como os grandes ancestrais. Ou seja, tanto "Mpungu", "ampungu" ou "ampunga" são palavras provenientes da língua bantu que se referem aos mortos, aos antepassados. Daí o grupo sair às ruas no dia primeiro de novembro, dia de Todos-os-Santos e véspera do dia de Finados, momento em que toda a população local tem sua atenção voltada para a lembrança de seus mortos, que são homenageados com flores, velas e missas - na tradição católica. Segundo Lopes, em todas as religiões bantas, os espíritos dos ancestrais são os intermediários entre a divindade suprema e o homem; "são eles que

7 Zamiapunga; zabiapunga; zameapunga ou. Ver: BIANCARDI, Emília. Raízes Musicais da Bahia; ARAUJO, Nelson de. Pequenos Mundos; CASTRO, Yeda Pessoa de. Falares Africanos na Bahia.

8 CASTRO, P. Yeda. Etnolinguista baiana que estudou na África. 
levam as oferendas dos fiéis e intercedem em seu favor junto a Nzambi" (LOPES, 2006, p. 262-263).

É provável que o Zambiapunga do Baixo Sul baiano fosse ou integrasse um ritual religioso de uma parcela dos africanos escravizados. Aliás, o lugar abrigara vários quilombos no final do século XIX. Segundo Nélson de Araújo, baseando-se em depoimentos de Miguel Araújo, o Zambiapunga "era um ato religioso, em que se empregavam máscaras para afugentar os maus espíritos" (ARAÚJO, 1986, p. 81). Já João José Reis diz que os escravos aproveitavam, desde os tempos coloniais, “ $\mathrm{O}$ calendário de festas católicas para produzir paralelamente suas próprias comemorações" (REIS, 1991, p. 21), sem gerar suspeitas sobre suas crenças religiosas.

Os negros bantos faziam esses cultos aos deuses, em adoração aos seus entes queridos, mortos por enfermidades ou nas guerras, nos combates contra seus inimigos - negros de outras aldeias. Atualmente, não mais existe a mesma devoção; o grupo Zambiapunga vai às ruas com sentido de brincadeira, alegria e festa. Segundo Emília Biancardi, "a brincadeira ocorre à noite, percorrendo um trajeto mal iluminado, carregando tochas e fachos e dirigindo-se a uma encruzilhada, onde acendem velas, cantam e brincam" (BIANCARDI, 2000, p. 26).

Temos conhecimento de quatro pesquisas que tratam um pouco sobre o folguedo aqui em destaque. A primeira, Pequenos Mundos, de Nelson de Araújo (1986), é uma descrição das manifestações da cultura popular da Bahia; dividida em três tomos, o autor dedica aproximadamente sete páginas ao Zambiapunga, a partir de informações obtidas nesses municípios e na escassa bibliografia disponível sobre a manifestação. $\mathrm{O}$ livro da etnomusicóloga e pesquisadora da música folclórica brasileira, Emília Biancardi (2000), é a segunda obra; com seu interesse por instrumentos musicais da cultura popular, destina algumas páginas para descrever os exóticos e singulares instrumentos que compõem o ritmo e a caracterização do Zambiapunga.

A terceira é uma monografia de graduação em História que se limita apenas no folguedo de Nilo Peçanha, de autoria de Alexandre Guimarães (2003), historiador e ex-membro do mesmo grupo. A última, 
uma dissertação em Antropologia Social de cunho político no Baixo Sul baiano e que também enfoca o folguedo, da carioca Paula Siqueira (2006).

Esses olhares também ajudarão a compreender a dinâmica das singularidades do Zambiapunga, bem como entender as transformações e as permanências do cotidiano dos integrantes dos grupos, pois, no decorrer dos estudos, nortearam as seguintes perguntas: como o Zambiapunga, a partir de sua natureza de festa, de manifestação cultural, regional e local, busca a ressignificação da memória e da identidade dos membros das comunidades? De que maneira os elementos constituintes, como a dança, a máscara, os instrumentos, as coreografias, cooperam com os processos educacionais no âmbito da manifestação aqui pesquisada?

Para responder a essas questões foi imprescindível a incursão etnográfica nas quatro cidades do objeto pesquisado, privilegiando-se os momentos em que haveria maior possibilidade de recolher dados (nas festas de largo, nos feriados), para que, dessa forma, seguindo os passos de DaMatta (1987) e de Marconi (1985), procurássemos vivenciar o campo através da permanência nos espaços pesquisados. Os registros dos eventos e da convivência com as comunidades foram relatados no diário de campo.

Portanto, para o desenvolvimento da pesquisa de campo, além do referencial antropológico, adotamos outras inspirações de investigação, como a pesquisa de campo, a escuta sensível, a observação participante, desvendando-se os fenômenos para além das aparências, aguçando o olhar e a fala para o mundo dos significados, não somente das vozes verbais, mas também das muitas falas não verbais, como o choro, os intervalos, o tom de voz, o silêncio ou os gestos - implícitos tão presentes em conversas entre pesquisadores e nativos, e cujo desvendamento implica em significados das ações e relações humanas - e a imersão na realidade observada, buscando, na convivência e na interação com os grupos zambiapunguenses, as relações construídas cotidianamente, para compreender com profundidade o fenômeno Zambiapunga.

Com esse olhar, Merleau-Ponty aponta: 
O mundo fenomenológico não é o ser puro, mas o sentido que transparece na intersecção de minhas experiências com aquelas do outro, pela engrenagem de umas nas outras; ele é, portanto, inseparável da subjetividade e da intersubjetividade que formam sua unidade (MERLEAU-PONTY, 1999, p. 18).

Compreende-se, através da fala do autor, que a maior importância no campo da fenomenologia é unir o subjetivismo ao objetivismo em sua noção de mundo. Para Macedo: “A observação participante é como uma busca pelo conhecimento, onde este é gerado pela interação com a prática participativa. Mas, também é uma técnica que possui como desvantagem o risco da comunidade não aceitar o pesquisador, sentir antipatia, estranheza e ignorá-lo" (MACEDO, 2010, p. 154). No entanto, o fato de um dos autores deste texto residir na Ilha por três dias na semana, em função do trabalho educacional que vem sendo desenvolvido com a comunidade, contribui, maiormente, com o compromisso, alargando os laços de convivência e respeito. A participação da comunidade estreitou ainda mais os laços entre a pesquisadora e os atores sociais. Procuramos trazer o de mais natural nas falas e olhares críticos, questionadores, reflexivos, buscando dialogar com as percepções do campo com a Literatura, observando, através das vicissitudes, o verdadeiro trejeito 9 na veracidade dos fatos.

Segundo Antônio Carlos Gil (1999), na pesquisa de campo, através da "escuta sensível", a ênfase está, por exemplo, na análise da estrutura do poder local ou das formas de associação verificadas entre os integrantes da comunidade entrevistada. A observação participante consiste na participação real do conhecimento na vida da comunidade, do grupo ou de uma situação determinada. Essa técnica aproxima o conhecimento do grupo a partir do interior dela mesma. Portanto, além da observação participante, as entrevistas e gravações audiovisuais foram também utilizadas como instrumentos de análise, para obtermos os resultados adquiridos durante todo o tempo do trabalho de campo.

Foram feitos registros da fala de alguns moradores das quatro cidades aqui já citadas que, durante a fase de observação, demostraram possuir

9 Gesto; careta; esgares. 
ligação com a temática da pesquisa, sendo que, entre esses entrevistados, estiveram presentes pessoas da comissão organizadora das procissões e das lavagens da igreja, antigos e atuais organizadores das festas, assim como os líderes e integrantes dos grupos Zambiapunga, todos ligados à cultura popular local.

Nessas visitas aos moradores, na maioria das vezes não agendadas, porque costumavam citar ditados populares como "Na casa onde falta pão, faltam os amigos"; "Quem a minha casa não vai, da sua me corre"; "Casa do pai, escola do filho"; "Casa onde comem dois, comem três", cujas interpretações diziam que já éramos de casa, que não precisávamos bater à porta, apenas levar o pó de café e juntar-se a eles. As reuniões aconteciam à noite ou nos finais de semana, quando ali estávamos. Mas, para que isso acontecesse, utilizando a fala de Macedo, foi "necessário conviver com o desejo, a curiosidade, a criatividade humana; com suas utopias e esperanças; com a desordem e o conflito; com a precariedade e pretensão; com as incertezas e os imprevistos" (MACEDO, 2010, p. 69).

A seguir, apresentamos os processos educacionais vistos como relações humanas de trocas e aprendizagens, assim como a memória e a identidade de moradores e representantes dos grupos Zambiapunga - importantes na formação dos indivíduos e nos espaços de interação com as pessoas. Macedo descreve-os como etnotextos ou "fixadores de experiências", que atestam a realidade cotidiana como "registro objetivo do vivido" (MACEDO, 2010, p. 51).

\section{Os lugares da memória e da identidade}

Falar de memória e identidade é, antes de tudo, falar de uma faculdade humana. A faculdade de conservar estados de consciência passados e tudo o que está relacionado a eles. René Silva abrilhanta: “A faculdade da memória é responsável por nossas lembranças do extenso campo de estudos sobre a memória, todavia, todos eles estão substantivamente articulados com noções de identidade, patrimônio material, imaterial e cultura popular" (SILVA, 2008, p.15).

A descrição dos entrevistados que se segue confirmará o que René 
Silva (2008) denomina de "lembranças articuladas à identidade"; e o que Candau (2014) sustenta: tanto a memória quanto a identidade estão indissoluvelmente ligadas, conjugam-se e se nutrem mutuamente, apoiam-se uma na outra para produzir uma trajetória de vida, uma história, um mito, uma narrativa. A transcrição das falas traz não somente relatos das festas e dos cortejos da manifestação aqui em destaque, mas também recordações, "causos" e narrativas vivenciadas por pessoas da localidade que tiveram contato com as ancestralidades; através dessas narrativas, levaram-nos a conhecer a comunidade e os acontecimentos que marcaram épocas, proporcionando-nos aprendizado e conhecimentos em busca da valorização da cultura local. Halbwachs fala sobre a importância de se recordar experiências e acontecimentos vividos em grupos ou numa comunidade:

Toda memória se estrutura em identidades de grupo: recordamos a nossa infância como membros e a partir de experiências numa vida em família, o nosso bairro como vizinhos em uma dada comunidade, a nossa vida profissional em torno de relações estabelecidas [...] (HALBWACHS, 2008, p. 86).

Compreende-se que tanto o social está inscrito na memória individual quanto a mesma memória se encontra enraizada na sociedade. $\mathrm{O}$ autor ainda diz mais: "Memórias são acontecimentos vividos pessoalmente e acontecimentos vividos pelo grupo ou pela coletividade à qual a pessoa se sente pertencer" (HALBWACHS, 2008, p. 86). Os protagonistas mais antigos contam que o Zambiapunga surgiu em Cairu, a partir de 1800, com Militão Rogério, filho de escravos. Seu Afonso descreve, juntamente com seus conterrâneos, a brincadeira:

Zambiapunga começou numa brincadeira com os filhos de escravos na fazenda em Cairu que tinha muita piaçava e os trabalhadores eram tudo escravos. Quando era noite de lua, não tinham o que fazer, tirava as enxadas do cabo, cada um com sua enxada na mão, arranjavam tambor de carneiro, faziam aqueles tambores bonitos, faziam aquelas caixas né!, arranjavam búzios da costa [...] pra fazer o purupupu [imita o som do búzio] . Então faziam aquelas meialua, uns batendo caixa, outros batendo enxada, outros tocando búzio, e faziam aquela brincadeira. E Militão Rogério era filho de 
escravo. Quando acabou a escravidão Militão Rogério continuou fazendo a brincadeira com os operários da serraria... (Seu Afonso - 65 anos de idade, comerciante. A partir dos 10 anos de idade, começou a participar do Zambiapunga, e recorda que gostava de bater na enxada).

O depoimento de Seu Afonso Magalhães coincide com o de Seu Zuca, quando atribuem aos escravos a origem do Zambiapunga. Esse último narrador ainda comenta uma situação, contada por seus pais, que descreve uma remota apresentação dos trabalhadores escravos produzindo sons com enxadas e búzios:

Meus pai disseru que veio dos africano. Contava que em 1811 quando um descendente dos donatário da capitania de Ilhéus resolveu mudar a povoação de Velha Boipeba, com o nome Nova Boipeba, os visitantes já foram saudados por enxada e búzio. Então, desde aquela época eu acredito que já existia o Zambiapunga. (Seu Zuca - ou melhor, Mestre Zuca é um dos sobreviventes da primeira fase do folguedo; hoje, com 71 anos de idade, toca tambor).

Veio de Cairu, começou com escravos das fazendas que tinha lá de piaçava. Vixe! Naquela época era animado eu fazia parte do Bumba-meu-Boi, mulher não saía no Zambiapunga não, era só pra homi. Mas mesmo assim era uma folia que todos participava. Quando era noite que sabia que ia sair o cortejo de madrugada nem dormia só pra esperar. Muita gente com candeeiro na mão, não tinha energia. Era festa bonita! (Dona Neide - uma das fundadoras do grupo Zambiapunga, com 85 anos de idade de pura alegria, disposição e boa memória. Conhece toda a história da manifestação e faz questão de salientar o amor pelas danças, pela seresta e pela boa cachaça).

Segundo Seu Geraldo, a origem do Zambiapunga de Nilo Peçanha, Valença e Taperoá liga-se à cidade de Cairu. Descrevendo o que escutou dos mais velhos, afirma que a manifestação, como até hoje, era levada às ruas nos dias de Santo, e também em $1^{\circ}$ de novembro. Chico Ribeiro10, vendo o cortejo em Cairu e gostando, resolveu reproduzi-lo em Nilo Peçanha, o que, com o tempo, tornou-se tradicional:

10 Pessoa que comandou o grupo em Nilo Peçanha/BA. 


\begin{abstract}
Quando terminou a igreja de Nossa Senhora do Rosário, o pessoal, pra fazer a festa, saiu batendo aquele negócio de enxada, careta, aí transformou em tradição. Aqui foi seu Arlindo que botou o grupo, Em Nilo (Peçanha) foi Chico Ribeiro, ele era de Cairu, que naquela época era intendente, [...] daí ele formou muita amizade em Nilo e foi com os homens daqui pra ensinar o pessoal a bater enxada [...] Cornélia, que morreu com 140 anos falava disso pra gente. (Seu Geraldo - "do Cavaquinho", como é conhecido, é cantor, compositor e ex-integrante do Zambiapunga. Tímido, porém muito vaidoso e dono de uma voz grave e afinada, tem orgulho de retratar, nas suas composições, a beleza da região em que vive).
\end{abstract}

Leomária, que nasceu em outra época, afirma, com o mesmo empenho do Seu Geraldo, o ponto de partida do Zambiapunga na região:

A origem do Zambiapunga é exatamente das cidades de Nilo Peçanha, Taperoá, Valença, Cairu, região quilombola... tem uma comunidade lá, quilombola do nome Itiúca se não me engano, o nome do lugar, é também remanescente né, é quilombola também, então assim, deve ser, eu pressuponho que são heranças daquela cultura, como a gente tem a capoeira, o samba de roda, os contos e tudo mais... (Leomária - 40 anos de idade, solteira, professora; nasceu na região e, ainda criança, foi morar em Salvador. Hoje, retornou para sua cidade natal. Acumulou muitos conhecimentos sobre a cultura popular local, mediante o contato com alunos e moradores, de forma investigadora, curiosa e direta com os sujeitos que vivenciaram e vivenciam o Zambiapunga).

Dona Neide reproduz a fala de Seu Afonso, quando diz que a manifestação é originada dos negros filhos de escravos das fazendas de Cairu. Para Halbwachs (2008), é possível que duas ou mais pessoas que presenciaram um mesmo fato o reproduzam com traços idênticos, quando o descreverem algum tempo depois. Segundo o autor, é chamada de "ordem dos detalhes" a importância relativa das partes e o sentido geral de acontecimentos:

Eu saía no Zambiapunga. A gente saía uma vez no ano só. Só saía no Dia de Reis. A gente descia aqui de madrugada, depois de meia noite. Andava por cá assim, [aponta para descida do cemitério] mais tinha uma lanterninha que clareava tipo uma sanfona assim de papel que fazia. Tinha muitos, e era todo mundo adulto, era 
uma brincadeira que tinha muita gente, a gente fazia um cordão grande lá, o pessoal tudo acompanhando, muita gente tocando e bem animado. (Seu Tião - 65 anos de idade, filho de pescador e ex-integrante do grupo Zambiapunga. Acompanhou desde pequeno as transformações do folguedo; fez parte da primeira fase e diz que, hoje, é tudo muito diferente da época dele).

Era janeiro, Festa dos Reis. Era uma roupa muito bonita, simples, mas muito bonita, um macacão estampado. Saía também de Cairu, de Maricoabo [Valença], saia de Nilo [Nilo Peçanha] e Taperoá, mas o pessoal dizia que o melhor era o daqui. Zambiapunga daqui! Foi um senhor que viajava muito. Aí ele disse que teve lá em Salvador, também disse que em Salvador ele viu. Aí chegou aqui ele fez o Zambiapunga. (Dona Neide).

Aqui a folia saía na Festa de Reis, era uma movimentação danada, muita gente, era animado. De um lado os homens mascarados e do outro as mulheres dançando em volta do Boi Janeiro. Mas o Zambiapunga saía acordando a gente de madrugada, descia o cemitério e passava pelos passeios da casa... depois juntava com os demais já com sol alto. (Seu Zuca).

Antigamente saía o grupo em janeiro, na Festa de Reis, hoje saímos em junho na festa do padroeira. Ensaiamos aqui [na Casa de Cultura Anália] na quinzena que antecede a festa. (Wesley - 18 anos de idade, estudante, coordenador do Coral Jovem e tocador de búzio. Neto de dona Anália e bisneto de dona Neide. Um dos jovens mais atuantes no grupo Zambiapunga).

Com dez anos entrei pro grupo, com essa idade entrava já, naquele tempo não tinha esse negócio de ir pra casa cedo... Naquela época a turma tinha influência, a Zambiapunga era mais de umas vinte e cinco pessoas, trinta, quarenta pessoas. Gostava de mexer mais com a enxada e o búzio. Era tudo bem arrumado. (Seu Afonso).

Observa-se que, antigamente, o cortejo saía somente na madrugada da Festa de Reis, diferente de hoje, em que as comunidades se apresentam nos dias do Padroeiro das suas cidades e/ou tradicionalmente, na antevéspera do dia dos Finados, o que o relacionava a seu real sentido Deus Supremo dos defuntos e como adoração aos entes queridos. Nota-se que, desde aquela época, as crianças já participavam das apresentações, com o intuito de dar continuidade ao grupo. O que não aconteceu com a professora Leomária, que nasceu no vilarejo, mas que viveu boa parte da sua infância e adolescência em Salvador, com sua mãe de criação, 
voltando só adulta a morar lá. Ela diz que a primeira vez em que presenciou o cortejo em Cairu ainda estudava lá:

Eu na verdade não era nascida ainda, eu acredito que isso aconteceu na década de 60 , final da década de 60 pra início da década de 70, mas na verdade eu não fui criada por minha mãe biológica e a minha mãe de criação Nair Magalhães que era soteropolitana, ela chegou a Boipeba em 1928... A primeira vez que eu vi uma manifestação dessas foi em Cairu, não foi em Boipeba, eu fazia faculdade lá de Pedagogia e eu lembro, como se fosse hoje, que o meu professor de História, ele pediu... Ele via a história muito clara, cada casarão de Cairu, cada esquina que a gente andava e ele pediu, pediu que as turmas fizessem uma manifestação cultural da cultura local e me surgiu essa Zambiapunga, assim do nada, e tãtãtãrantãtã... [imita o som do búzio] aquele som e eu... e aquele povo com careta e tal e eu falei, gente, que coisa interessante que é isso...... (Leomária).

Com Wesley aconteceu de forma diferente, pois seu conhecimento pela manifestação se deu desde pequeno, porque participava dos eventos com sua avó, dona Anália ${ }^{11}$.

Eu conheço um pouco sobre a história... porque foi trazida para Boipeba há três décadas, tem mais de 30 anos. Aí o pessoal dizia que era pra acordar a população para louvar as festas religiosas e normalmente o Zambiapunga quando sai, ele tem que ir pra porta da igreja, desce o cemitério e vai acordando o povo na madrugada com som de enxada e búzios. Desde pequeno via minha avó Anália comentar sobre meu bisavô Arlindo que iniciou com o grupo aqui em Boipeba. E sempre participei diretamente e indiretamente do Zambiapunga. Quando era criança me carregavam para os ensaios e agora participo como tocador de búzio e as vezes toco o tambor. (Wesley).

Percebe-se que, apesar de ambos, Wesley e Leomária, não terem participado diretamente da trajetória inicial do Zambiapunga, eles mostram que conhecem seu referencial histórico e identitário. Através das falas, é percebida a importância dada à manifestação, assim como o pertencimento e a forte identificação com a mesma. Como nos diz

11 Representante maior do grupo Zambiapunga de Ilha de Boipeba-Cairu. 
Cunha, "é preciso lembrar que os referenciais de tempo e de espaço são centrais na experiência identitária de cada indivíduo ou grupo, utilizados para a sua construção identitária, sua diversidade e ao processo de comunicação" (CUNHA, 2002, p. 33). Assim, as narrativas a seguir confirmam a forte ligação entre folguedo e morador; entre o olhar, ligado à memória cultural, e o falar, à identidade local:

Quando me visto, coloco minha máscara e pego minha enxada... me transformo num ser grande, poderoso e de mucha fé. Um Zâmbia tem poder, é forte! (Seu Zuca).

Mesmo não tando na frente mais do grupo, eu sou Zambiapunga porque sou de Ilha de Boipeba, porque meus ancestrais viveu isso, foi isso no passado. Para onde eu vou, digo que sô... (D. Neide).

Zambiapunga para mim é representação da minha cultura, assim como também me identifico com o teatro, na igreja, com o grupo jovem daqui... é nosso! É daqui, entende? (Wesley).

Eu sou negra. Eu amo ser negra, eu amo a história daqui, a minha história e em nenhum Censo [do IBGE] que eu tenha feito, eu nunca me coloquei parda, morena não... e ser daqui e ser principalmente negra é ser também um membro Zambiapunga, porque faz parte de todos que nascem aqui. Então... é um orgulho muito grande, que ao mesmo tempo que a história é triste, de como nós chegamos aqui, do que foi feito, também houve um período de superação de tudo isso. A gente ainda tá em um processo de superação, de se ver. (Leomária).

São esses alguns dos testemunhos de pessoas que nasceram e que vivem para a arte da cultura Zambiapunga. Não são quaisquer moradores que se instalam e que vivem de maneira rotineira e pacata num lugarejo cercado de belezas naturais, mas sim pessoas que se identificam como sujeitos-Zambiapunga, mergulhados na magia de poder e fortaleza dos deuses Nzambi-a-Mpungu, tendo, como referência maior, a história dos ancestrais escravos que vieram de terras longínquas e que instalaram o folguedo na região. 


\section{Os processos educacionais junto à Cultura do Zambiapunga}

Nos primeiros momentos no campo, investigando os processos de educação como um todo, incluindo o espaço escolar, entre os entrevistados, surgiram algumas inquietações e prerrogativas de que os lugares da educação contribuíram para a retirada de alguns zâmbias de seu lócus, modificando, assim, algumas características básicas da cultura do Zambiapunga. Saviani (1994) afirma que existem alguns aspectos que devem ser relevados quanto à relação entre educação e escola, sendo que esta última está ligada aos processos econômicos e sociais da época e às dificuldades de locomoções entre as localidades.

Se a escola é vista como planejamento para se galgar novas oportunidades de trabalho, os grupos que não estão diretamente inseridos no mercado de trabalho (por viverem no meio rural e terem sua forma social e cultural diferentes do meio urbano, em sua maioria) acabam não se interessando pelas informações oferecidas pelas escolas, e até resistem. Saviani afirma: "A forma escolar emerge como forma dominante de educação na sociedade atual. Isto a tal ponto que a forma escolar passa a ser confundida com a educação propriamente dita" (SAVIANI, 1994, p. 153). Assim, hoje, quando se pensa em educação, automaticamente, pensa-se em escola.

Porém, tentaremos ampliar essa compreensão; para isso, trazemos aqui alguns princípios da Educação Popular fundamentada nos escritos de Paulo Freire, como balizadores dos processos educativos envolvendo o Zambiapunga, e pelos quais se busca o diálogo, a integração e a participação dos indivíduos, através de uma educação comprometida com a conscientização e a politização do educando com o meio em que vive como sujeito ativo capaz de refletir e agir sobre ele (FREIRE, 1980).

Assim, o desafio que se coloca é justamente o fato de a escola, de a própria comunidade e de os zambiapunguenses mais experiente, encontrarem meios e espaços com o intuito de promover o diálogo com os demais jovens, para que os laços humanos sejam construídos e para que aconteça o que Freire preconiza: uma educação comprometida com a conscientização, transformando-os em sujeitos participativos com sua 
comunidade. Um dos objetivos da Educação Popular de Freire é inserir o sujeito no mundo, de fazer-se reconhecer a ele mesmo como cidadão, um ser indispensável nas relações sócio político-culturais do meio em que vive.

Sendo assim, destacamos os ensaios do grupo Zambiapunga como os lugares onde mais se potencializam os diálogos entre todos os participantes, pois a maioria dos jovens se faz presente, pela grande identificação com a parte musical percussiva. Nesses encontros, os espaços são considerados educativos, o que Freire anunciou ser o "dado fundamental das relações de todas as coisas do mundo" onde se tem a troca de experiências e comunicação, se gera diálogo e ação. Para o pedagogista, "o diálogo é o sentimento do amor tornando ação" (FREIRE, 1980, p. 103).

Para Brandão (2008), a finalidade da educação está atrelada ao desenvolvimento do processo de humanização das pessoas, que se efetiva através do diálogo, já que este se constitui como elemento fundamental para a humanização. Para o autor, o diálogo torna-se a essência de uma educação humanizadora e se constitui como fenômeno essencialmente humano, realizado pelas pessoas, por meio da palavra, a partir de duas dimensões: a ação, para a transformação e a não alienação, e a reflexão, atrelada à conscientização crítica e não alienante.

No grupo Zambiapunga estudado, a comunicação é tida como elemento gerador de ação; o representante, ao ser ouvido, convida os demais integrantes a assumirem uma posição ativa no mundo frente às situações vividas, a fim de expressarem a sua voz diante de toda a estrutura que os incomodam. Portanto, o ato de falar deve ser suscitado de forma que venha a contribuir no processo de desenvolvimento desses jovens, numa perspectiva de fazer educação numa ação democrática e não autoritária.

Outro lugar de potencialização entre os zâmbias são as reuniões de grupo, que se fazem necessárias antes dos eventos culturais acontecerem. Notamos que a "velha guarda" leva sempre palavras de incentivo ao grupo, pois, se para os ensaios eles podem contar com a presença de todos os integrantes, nas reuniões de grupo, isso não acontece. As decisões e 
os trabalhos mais cansativos ficam para os idosos executarem. Para os líderes do grupo, é preciso convocar os mais jovens para as reuniões, para que estejam presentes e, dessa maneira, haja construção do conhecimento de forma cooperativa, com diálogo, com interação, em comunhão com o outro, proporcionando trocas, buscando fazer uma inter-relação com questões de cunho étnico, político, econômico, religioso, social e também cultural.

Observa-se que a proposta daqueles que estão mais engajados com os grupos é algo que se caracteriza por uma prática conscientizadora, comprometida com o fortalecimento e com a continuidade ao que deles é herdado; uma manifestação com características singulares, somente existente em sua região. Como alerta Brandão: “Uma prática cultural e educadora deveria envolver um trabalho intelectual de reelaboração dos elementos ideológicos da tradição de um povo" (BRANDÃO, 2008, p. 29).

A responsabilidade dessas pessoas que estão à frente desses grupos culturais é grande. Eles precisam dialogar sobre a importância do grupo a todo o momento, pois a própria sociedade não valoriza esses movimentos culturais; nesse sentido, a autoestima dos participantes precisa ser sempre estimulada, somada à conscientização do papel de cada um para o fortalecimento do grupo. Isso contribui para a autonomia dos sujeitos, e essa autonomia, quando acontece na práxis, contribui para o desenvolvimento de uma consciência crítica, pautada na reflexão dos seus e dos outros, criando e fortalecendo parâmetros, valores, aprendizados, ações que repercutem em um ciclo de reflexões voltadas a ações para uma vida comunitária mais humana e harmoniosa.

A ação libertadora, pelo contrário, reconhecendo esta dependência dos oprimidos como ponto vulnerável, deve tentar, através da reflexão e da ação, transformá-la em independência. Esta por mais bem-intencionada que seja, lhes faça. Não podemos esquecer que a libertação dos oprimidos é libertação de homens e não de "coisas". Por isso, se não é autolibertação - ninguém se liberta sozinho -, também não é libertação de uns feita por outros. (FREIRE, 1980, p. 60).

Percebe-se que, no processo educativo e dialético proposto por Freire, o sujeito é demonstrado como autor primeiro, consciente e 
responsável dos desafios que o cercam. Nesse sentido, a partir dessa visão, é imprescindível que a comunidade e a escola se envolvam de forma mais ativa e participativa nas manifestações e nos eventos do lugar, incluindo-se representações estudantis que possam participar tanto nas apresentações nos dias festivos quanto nos ensaios e nas reuniões de grupo. Um trabalho realizado de forma articulada, que destaque o papel do zambiapunguense na valorização das manifestações culturais, da memória e da identidade, tornando-os mais próximos da história do lugar em que moram e de sua própria história. Além disso, uma conscientização cidadã em relação aos problemas locais estaria sendo estimulada, porém, o desafio é de que a comunidade tome para si a proposta e se empenhe em concretizá-la, com táticas e estratégias mobilizadoras.

Esse é um processo que toma lugar não somente na sala de aula, mas também num espaço de aprendizagem que Freire (1980) denomina de "círculo cultural". Este pode ser representado pelos espaços frequentados pelo Zambiapunga: lugares de ensaios, lugares das apresentações, lugares de reuniões. Enfim, lugares que, na visão do pedagogo, são amplitudes de um ambiente de aprendizagem não restrito à sala de aula, que favoreça também o processo de aprendizagem.

Constata-se que o grupo Zambiapunga se apresenta nos espaços de "círculo cultural", assumindo um compromisso, ao promover práticas de formação política e sociocultural, com o desenvolvimento da consciência crítico-reflexiva, capacitando "os indivíduos a se posicionarem enquanto cidadãos do mundo, no mundo" (GOHN, 2006b, p. 29). Dessa forma, o folguedo será levado adiante pelos sujeitos que representam o futuro e a permanência dessa manifestação, contribuindo, assim, para a ressignificação da memória e da identidade dos membros da comunidade local.

Portanto, percebemos que os elementos constituintes do Zambiapunga permitem a seus integrantes a construção de uma identidade, pois, para eles, utilizarem as indumentárias e tocarem seus tambores, enxadas e búzios ou até mesmo estarem presentes no dia das apresentações são momentos de reafirmarem a sua presença perante a comunidade em que 
vivem, cuja plenitude ultrapassa o dia oficial da brincadeira. Dessa forma, esses indivíduos zambiapungueses contribuem para a ressignificação da cultura local, da identidade dessas localidades e da memória dos seus ancestrais. Portanto, compreendemos que ninguém nasce um Zâmbia, torna-se um Zâmbia!

Quanto aos processos educacionais no âmbito da manifestação cultural, que envolvem o diálogo e que estimulam a preservação, a promoção e a difusão da cultura local, o comprometimento da comunidade nos espaços de aprendizagens e as potencializações, faz florescer vínculos que se formam e que dão continuidade aos saberes e fazeres tradicionais da comunidade. Vínculos importantes na formação dos indivíduos e nas atualizações dos espaços de interação das pessoas do lugar, no qual a convivência educa e forma, quando pautada no respeito pelo diferente, ao estabelecer relações humanas de trocas.

Por fim, em termos gerais, fica explícita, nos depoimentos dos integrantes e moradores das cidades de Valença, Nilo Peçanha Taperoá e Cairu, a ressignificação pela manifestação popular através da história, da identificação e do sentimento de pertencer ao grupo Zambiapunga.

Um pertencer bastante particular, legado de cultura e de ancestralidade africanas, no qual vão se construindo as identidades dos sujeitos zambiapunguenses de forma mais ativa e comprometida com sua própria comunidade, onde evidencia-se a sua valorização enquanto sujeitos protagonistas de sua cultura e onde se percorre uma senda estreita, entre abraçar o moderno e reverenciar o passado.

\section{Referências}

ABIB, Pedro Rodolpho Jungers. Capoeira Angola: cultura popular e contemporaneidade. Revista Patrimônio e Memória, São Paulo, v.11, n.1, jan. 2015.

ARAÚJO, Nélson de. Pequenos Mundos: um panorama da cultura popular baiana. Salvador: Egba, 1986. 
BIANCARDI, Emília. Raízes Musicais da Bahia. Salvador: Secretaria da Cultura e Turismo, 2000.

BRANDÃO, Carlos Rodrigues. Cultura popular em sociedades contemporâneas. Cadernos de Pesquisa, São Paulo, v. 39, n. 138, 2008.

A cultura na rua. São Paulo: Papirus, 1989.

BRASIL. Ministério da Cultura. Plano Setorial para as Culturas Populares. Brasília, DF: Secretaria da Identidade e diversidade Cultural, 2012.

CANDAU, Joel. Memória e identidade. Trad. Maria Leticia Ferreira. São Paulo: Contexto, 2014.

CASTRO, Yeda Pessoa de. Falares africanos na Bahia: um vocabulário afro-brasileiro. Rio de Janeiro: Topbooks, 2002.

CUNHA, Maria Clementina Pereira. Carnavais e outras $\mathbf{f}(\mathbf{r})$ estas: ensaios de história social da cultura. Campinas: Unicamp, 2002.

DAMATTA, Roberto. Relativizando uma introdução à antropologia social. Rio de Janeiro: Rocco, 1987.

FONSECA, Raimundo Nonato da Silva. Fazendo fita: cinematógrafos, cotidiano e imaginário em Salvador, 1897-1930. Salvador: Edufba, 2002.

FREIRE, Paulo. Conscientização: teoria e prática da libertação - uma introdução ao pensamento de Paulo Freire. 3. ed. São Paulo: Moraes, 1980.

GIL, Antônio Carlos. Métodos e técnicas de pesquisa social. 5. ed. São Paulo: Atlas, 2003.

GOHN, Maria da Glória Marcondes. Educação não-formal, participação da sociedade civil e estruturas colegiadas nas escolas. Aval. pol. públ. Educ., Rio de Janeiro, v. 14, n. 50, p. 27-38, jan./mar. 2006b. Disponível 
em: <http://www.scielo.br/pdf/ensaio/v14n50/30405.pdf>. Acesso em: 13 jul. 2015.

GUIMARÃES, Alexandre A. B. Zambiapunga de Nilo Peçanha: representações no tempo (1940-2002). Monografia (Graduação em História) - Universidade do Estado da Bahia, Santo Antônio de Jesus, BA, 2003.

HALL, Stuart. A identidade cultural na pós-modernidade. Rio de Janeiro: DP\&A, 2002.

HALBWACHS, Maurice. A memória coletiva. São Paulo: Vértice; Ed. dos Tribunais, 2008.

LOPES, Nei. Bantos, malês e identidade negra. Rio de Janeiro: Autêntica, 2006.

MACEDO, Roberto Sidnei. A etnopesquisa implicada: pertencimento, criação de saberes e afirmação. Brasília, DF: Liber Livro, 2012.

MARCONI, Marina de Andrade. Antropologia: uma introdução. São Paulo: Atlas, 1985.

MERLEAU-PONTY, M. Fenomenologia da percepção. 2. ed. São Paulo: Martins Fontes, 1999.

PRIORI, Mary Del. Festas e utopias no Brasil colonial. São Paulo: Brasiliense, 1994.

REIS, João José. Rebelião escrava no Brasil: a história do levante dos Malês. São Paulo: Companhia das Letras, 1991.

SAVIANI, Demerval. História das ideias pedagógicas no Brasil. 3. ed. Campinas: Autores associados, 2011. (Coleção Memória da Educação).

SILVA, René Marc da Costa. (Org.) Cultura popular e educação - salto 
para o futuro. Brasília, DF: TV Escola/SEED/MEC, 2008.

SIQUEIRA, Paula. Zambiapunga: cultura e política no Baixo Sul da Bahia. 2006. Dissertação (Mestrado em Antropologia Social)-Universidade Federal do Rio de Janeiro, Rio de Janeiro, 2006. 